\title{
Clinical presentation and complication of chronic suppurative otitis media with cholesteatoma in a rural setting
}

\author{
MS Islam ${ }^{1 凶}$, MA Gafur ${ }^{2}$, L Noor $^{3}$, MR Islam ${ }^{4}$
}

\begin{abstract}
To study the clinical presentations of chronic suppurative otitis media (CSOM) with cholesteatoma and its complication, 96 patients with CSOM from ENT department of a medical college hospital during January 2011 to January 2014 were included in this study. The highest number of cases belonged to the age group of $11-20$ years $(55.2 \%)$, and the number of males and females was $67.2 \%$ and $32.8 \%$, respectively. Almost all the patients presented with multiple symptoms. The most common symptoms were discharge from ear(s) (100.0\%), hearing impairment $(83.3 \%)$, earache $(15.6 \%)$, fleshy mass in ear(s), etc. Of the patients, $67.9 \%$ cases were without complication, $26.1 \%$ with extracranial complication and $6.3 \%$ with intracranial complication. All the cases had a perforation either in the posterior superior marginal $(66.5 \%)$ or in the attic region (33.5\%). Most of the patients were having unilateral CSOM with cholesteatoma, in the right side $(64.3 \%)$, left side $(35.7 \%)$, and a few $(4.2 \%)$ bilateral involvement. Although $83.3 \%$ of the patients complained of deafness, audiometric tests were done in $93.7 \%$ of the patients excluding $6.4 \%$ who had intracranial complication. All of them (93.7\% tested) had developed deafness; mild deafness $(20.0 \%)$, moderate deafness $(77.8 \%)$, and severe deafness $(2.2 \%)$. In conclusion, the pattern of clinical presentation and complication of CSOM with cholesteatoma in rural setting may be similar with the pattern involving urban population and early diagnosis of CSOM with cholesteatoma by taking proper history and clinical examination, and timely surgical intervention may be helpful to eradicate the disease and prevent complications.
\end{abstract}

Key words: Cholesteatoma, chronic suppurative otitis media, clinical presentation, complication.

\section{Introduction}

Chronic suppurative otitis media (CSOM) is a perforated tympanic membrane with persistent drainage from the middle ear (lasting $>6$-12 weeks). ${ }^{1,2}$ Chronic suppuration can occur with or without cholesteatoma, and the clinical history of both conditions can be very similar. Cholesteatoma is a lesion of obscure origin, a slowly progressive and destructive of the middle ear cleft caused by formation of a whitish shiny bag or sac lined by stratified squamous epithelium containing layers of concentric keratin material impregnated with desquamated squamous epithelium with or without cholesterol crystal. It is capable of destroying soft and hard tissues surrounding it producing extracranial and intracranial complications. ${ }^{3}$ According to presumed etiology cholesteatoma may be congenital and acquired. The primary acquired cholesteatoma, the most common form of acquired cholesteatoma arises from a skin lined

1. MS Islam, Associate Professor, Department of ENT, Jahurul Islam Medical College Hospital, Kishoregonj

2. MA Gafur, Professor, Department of Anaesthesiology \& ICU, Ad-din Women Medical College Hospital, Dhaka

3. L Noor, Professor, Department of Obstetrics \& Gynaecology, Ad-din Women Medical College Hospital, Dhaka

4. MR Islam, Lecturer, Jahurul Islam Nursing College, Kishoregonj 
retraction pocket and the secondary acquired cholesteatoma develops from ingrowths of skin through a tympanic membrane perforation and secondary to episodes of inflammation where the mucosa undergoes metaplasia to squamous type. ${ }^{4-7}$ Clinical presentation of cholesteatoma in an uncomplicated case is usually discharge which varies from thick, purulent, foul smelling, scanty, occasionally bloodstained and cheeselike to clear and serous, and hearing loss in the affected ear. ${ }^{3}$ Small slow growing cholesteatoma can often be asymptomatic, only discovered as an incidental finding. However, in the presence of complication the patient may develop earache, fever, chill, rigor, post-auricular swelling, vomiting, vertigo, headache, postauricular discharging sinus, facial weakness, etc. $^{8-12}$ There are many cases with cholesteatoma present with extracranial complication and sometime with grave intracranial complication specially in case of children.

As cholesteatoma is considered unsafe because of the risk of developing complications particularly intracranial complication, early diagnosis and complete eradication are essential for the safety of patients. In a study by Yousuf et al, it was shown among urban and rural population that poverty, illiteracy, overcrowding, living in slum with kuntcha floor, bathing in ponds and river with the habit of swimming were the main etiological factors. ${ }^{13}$ This study was conducted among patients from rural population to ascertain the disease profile which may be helpful to enhance prompt diagnosis and treatment or early referral to reduce morbidity and mortality of the patients.

\section{Materials and Method}

A total of 96 patients visiting the Department of Otolaryngology \& Head Neck Surgery, Jahurul Islam Medical College \& Hospital during January 2011 to January 2014 for treatment of CSOM with definitive cholesteatoma were included in this study. The patients were diagnosed as CSOM with definitive cholesteatoma by taking history in detail in a prescribed study protocol and examination of ear, nose and throat including otoscopy under magnification. Radiological investigations included X-ray of mastoid bones in Towne's and Stenver's views and were done in all the cases. Audiometric investigations were done in patients without intracranial complication.

\section{Results}

Table 1 shows the age distribution of the patients. The highest number of patients were in the 11-20 years of age. In this study, the age of the patients ranged from 6 years to 40 years. The highest number of patients were in the $11-20$ years age group $(55.2 \%)$. The number of males and females was $67.2 \%$ and $32.8 \%$, respectively.

Almost all the patients presented with multiple symptoms. The most common symptoms were discharge from ear(s) (100.0\%), hearing impairment (83.3\%), earache $(15.6 \%)$, fleshy mass in ear(s), etc (Table 2$)$.

Table 3 shows the patients with extracranial and intracranial complications. Of the patients, $67.6 \%$ cases were without complication, $26.0 \%$ with extracranial complication and $6.4 \%$ with intracranial complication.

Table 1. Age and gender distribution of patients, $\mathrm{n}=96$

\begin{tabular}{lc}
\hline Characteristics & $\mathbf{\%}$ \\
\hline Age (years) & \\
$\leq 10$ & 18.8 \\
$11-20$ & 55.2 \\
$21-30$ & 15.6 \\
$31-40$ & 10.4 \\
Gender & \\
Male & 67.2 \\
Female & 32.8 \\
\hline
\end{tabular}

Table 2. Clinical presentation of chronic suppurative otitis media patients, $n=96$

\begin{tabular}{lr}
\hline Symptoms & $\mathbf{\%}$ \\
\hline Discharge from ear(s) & 100.0 \\
Hearing impairment & 83.3 \\
Earache & 15.6 \\
Fleshy mass in ear(s) & 15.6 \\
Post-auricular painful swelling & 12.5 \\
Post-auricular discharging sinus & 10.4 \\
Fever & 10.4 \\
Headache & 6.3 \\
Vomiting & 5.2 \\
Vertigo & 5.2 \\
Neck rigidity & 4.2 \\
Facial paralysis & 3.1 \\
Tinnitus & 2.1 \\
\hline
\end{tabular}


Table 3. The patients with extracranial and intracranial complications, $n=96$

\begin{tabular}{lr}
\hline Complications & $\mathbf{\%}$ \\
\hline Extracranial & \\
$\quad$ Post-auricular abscess & 12.5 \\
$\quad$ Post-auricular sinus & 10.4 \\
$\quad$ Facial palsy & 3.1 \\
Intracranial & \\
$\quad$ Extradural abscess & 1.1 \\
$\quad$ Lateral sinus thrombophlebitis & 1.1 \\
$\quad$ Meningitis & 3.1 \\
$\quad$ Temporal lobe abscess & 1.1 \\
\hline Total & 32.4 \\
\hline
\end{tabular}

Table 4. Audiometric findings of chronic suppurative otitis media patients with cholesteatoma, $n=90$ patients, 180 ears

\begin{tabular}{lr}
\hline Audiometric findings & $\mathbf{\%}$ \\
\hline Mild deafness $(26-40 \mathrm{~dB})$ & 20.0 \\
Moderate deafness $(41-70 \mathrm{~dB})$ & 77.8 \\
Severe deafness $(71-90 \mathrm{~dB})$ & 2.2 \\
\hline Total & 100.0 \\
\hline
\end{tabular}

All the cases had a perforation either in the posterior superior marginal $(66.5 \%)$ or in the attic region (33.5\%). Most of the patients were having unilateral CSOM with cholesteatoma, in the right side (64.3\%), left side $(35.7 \%)$, and a few $(4.2 \%)$ bilateral involvement. Table 4 shows the audiometric findings of CSOM patients with cholesteatoma. Although $83.3 \%$ of the patients complained of deafness, audiometric tests were done in $93.7 \%$ of the patients excluding $6.4 \%$ who had intracranial complication. All of them (93.7\% tested) had developed deafness; mild deafness $(20.0 \%)$, moderate deafness $(77.8 \%)$, and severe deafness $(2.2 \%)$.

\section{Discussion}

Ninety six CSOM patients of different age and sex were included in this study with definitive cholesteatoma after taking relevant history, clinical examination and investigation. In the present study, the highest number of cases belonged to the age group of $11-20$ years $(55.2 \%)$, and the number of males and females was $67.2 \%$ and $32.8 \%$, respectively. This is consistent with that reported in other studies. ${ }^{13-18}$

Almost all the patients presented with multiple symptoms. The most common symptoms were discharge from ear(s) $(100.0 \%)$, hearing impairment (83.3\%), earache $(15.6 \%)$, fleshy mass in ear(s), etc. Of the patients, $67.6 \%$ cases were without complication, $26.0 \%$ with extracranial complication and $6.4 \%$ with intracranial complication. All the cases had a perforation either in the posterior superior marginal $(66.5 \%)$ or in the attic region (33.5\%). This findings are consistent with those in other studies. ${ }^{11,13,19-21}$

Most of the patients were having unilateral CSOM with cholesteatoma, in the right side $(64.3 \%)$, left side $(35.7 \%)$, and a few $(4.2 \%)$ bilateral involvement. Although $83.3 \%$ of the patients complained of deafness, audiometric tests were done in $93.7 \%$ of the patients excluding $6.3 \%$ who had intracranial complication. All of them $(93.7 \%$ tested) had developed deafness; mild deafness $(20.0 \%)$, moderate deafness $(77.8 \%)$, and severe deafness $(2.2 \%)$. The results are similar to results reported by others. ${ }^{13,22-24}$

It was suggested that peoples living in rural and slum areas having swimming habit in ponds and rivers suffered more from cholesteatoma than who resides in the city and baths in supply water. ${ }^{13}$ However, the findings of this study involving rural population showed similar pattern of clinical presentation and complication of CSOM with cholesteatoma with the pattern involving urban population in other study. ${ }^{13}$

In conclusion, the pattern of clinical presentation and complication of CSOM with cholesteatoma in rural setting may be similar with the pattern involving urban population and early diagnosis of CSOM with cholesteatoma by taking proper history and clinical examination, and timely surgical intervention may be helpful to eradicate the disease and prevent complications.

\section{References}

1. Matsuda $Y$, Kurita $T$, Ueda $Y$, Ito $S$, Nakashima T. Effect of tympanic membrane perforation on middle-ear sound transmission. J Laryngol Otol 2009;123 (Suppl 31):81-9.

2. Wright D, Safranek S. Treatment of otitis 
media with perforated tympanic membrane. Am Fam Physician 2009;79(8):650-4.

3. Underbrink M. Cholesteatoma. In: Grand Rounds Presentation. Quinn FBJr, Ryan MW, (eds), UTMB, Department of Otolaryngology, September 18, 2002.

4. Gray RF, Howthrone M. (eds). Synopsis of Otolaryngology. 5th edn. Taylor \& Francis, 1992.

5. Kerr AG, Booth JB. eds. Scott Brown's Otolaryngology, Otology. 6th edn. London: Butterworth and Heinemann, 1997.

6. Podoshin L, Fradis M, Ben David Y, Margalit A, Tamir A, Epstein L. Cholesteatoma: an epidemiologic study among members of kibbutzim in Northern Israel. Ann Otol Rhinol Laryngol 1986;95:365-8.

7. Sadé J, Shatz A. Cholesteatoma in children. J Laryngol Otol 1988;102:1003-6.

8. Mawson SR, Ludman H, Wright T. (eds). Diseases of the ear. 6th edn. London: Edward Arnold, 1998.

9. Ballenger JJ. ed. Diseases of the Nose, Throat, Ear, Head and Neck. 13th edn. Philadelphia: Lea \& Febiger, 1985.

10.Savic LD, Deleric DR. Facial paralysis in chronic suppurative otitis media. Clin Otolaryngol 1989;14:515-7.

11. Edelstein DR. Parisier SC. Han JC. Acquired cholesteatoma in the pediatric age group. Otolaryngol Clin N Am 1989; 22(5):955-66.

12.Ludman $\mathrm{H}$. Complications of suppurative otitis media. In: Kerr AG, Booth JB. eds. Scott Brown's Otolaryngology, Otology. 5th edn. London: Butterworth; 1987.

13. Yousuf $M$, Majumder KA, Kamal A, Shumon AM, Zaman Y. Clinical study on chronic suppurative otitis media with cholesteatoma. Bangladesh J Otorhinolaryngol 2011;17(1):42-7.

14.Ludman H. Applied anatomy. In: Mawson's Disease of the Ear. 5th edn. London: Edward Arnold, 1988;17-25.

15.Amin MN, Chowdhury WA, Sheikh MS, Abdullah M. Pattern of ENT diseases in rural Bangladesh. Journal of BCPS 1989;7:23-27.

16.Shenoi PM. Management of chronic suppurative otitis media. In: Kerr AG, Booth JB. eds. Scott Brown's Otolaryngology, Otology. 5th edn. London: Butterworth; 1987.

17.Kemppainen HO, Puhakka HJ. Epidemiology and aetiology of middle ear cholesteatoma. Acta Otolaryngol 1999;119:568-72.

18. Browning GG, Pathology of inflammatory conditions of middle ear. In: Kerr AG, Booth JB. eds. Scott Brown's Otolaryngology, Otology. 5th edn. London: Butterworth; 1987.

19.Manni JJ, Lema PN. Otitis media in Darres Salam, Tanjania,J Laryngol Otol 1987; 101:222-8.

20.Ustun O, Cureoglu S, Otitis media, suppurative, complications. J Laryngol Otol 2000;114:97-100.

21.Amin ASA, Joardar MAH et al. A study on complications of chronic suppurative otitis media. Northern Medical Journal 1996;5:1-4.

22. Nasima Akter et al. Hearing loss in chronic suppurative otitis media, Bangladesh J Otorhinolaryngol 2003;9:19-23.

23. Alho OP, Jokinen $\mathrm{K}$ et al. Chronic suppurative otitis media \& cholesteatoma, Vanishing disease among western populations. J Otolaryngol 1997;22:258-61.

24.Chowdhury MA, Alauddin M. Comparative study between tubotympanic and atticoantral types of chronic suppurative otitis media. BMRC Bull 2002;28:36-41.

\section{Suggestion for citation of the above:}

Islam MS, Gafur MA, Noor L, Islam MR. Clinical presentation and complication of chronic suppurative otitis media with cholesteatoma in a rural setting. Mediscope 2017;4(2):25-8. 